\title{
The effects of some pharmacological agents on the duration of immobility shown by rabbits placed in various postures
}

\author{
KELLY P. FLANNIGAN and IAN Q. WHISHAW \\ University of Lethbridge, Lethbridge, Alberta, Canada TIK $3 M 4$
}

\begin{abstract}
Dutch belt rabbits placed in a number of postures remained immobile for longest durations in a back, shortest durations in a sitting, and for intermediate durations in side and front postures. Although atropine and chlorpromazine prolonged and eserine and amphetamine decreased immobility durations, the relative relation of posture to immobility duration was maintained. The drug treatments also affected the duration of spontaneously occurring periods of immobility in a way similar to that observed with induced immobility. There was an inverse relation between body core temperature and immobility duration. The results are discussed in relation to the relative contribution made by central and peripheral factors to the maintenance of immobility.
\end{abstract}

In recent years there has been increasing interest in the neurological mechanisms governing immobility. The immobility that results from experimental manipulation has been given a variety of names, among which the most popular are animal hypnosis (Carli, 1977), tonic immobility (Maser \& Gallup, 1977), and the immobility reflex (Klemm, 1971).

One method used to assess the influence of central systems on immobility is to treat animals with pharmacological agents (Hatton, Woodruff, \& Meyer, 1975; Klemm, 1965; Scotti de Carolis, Carruyo, \& Longo, 1968). In these experiments rabbits were placed on their backs and measures were taken on the durations they were still after receiving drug treatments. However, it was not clear whether the drugs were selectively affecting mechanisms which maintained the rabbit in an inverted posture or whether changes in durations were due to side effects of the drugs.

One way to control for side effects is to examine the influence of an experimental manipulation on different types of immobility as well as on immobility which occurs during spontaneous behavior. In the present experiment we describe the relationship between four postures and the duration of immobility. In addition, we examine the effects of a number of drugs on these postures and on spontaneously occurring immobility. Finally, we report a relationship between body core temperature and immobility duration.

This research was supported by Grant A 8273, awarded to Ian Q. Whishaw by the National Research Council of Canada. The authors thank Timothy Schallert for discussing many facets of the experiment, Bryan Kolb for useful comments on the manuscript, and Adria Allen for typing. Requests for reprints should be sent to Ian $Q$. Whishaw, Department of Psychology, University of Lethbridge, Lethbridge, Alberta, Canada T1K 3M4.

\section{METHOD}

\section{Subjects and Drugs}

The experiments used seven domestic adult Dutch belt rabbits. Each animal received intravenously via the marginal ear vein: atropine sulfate, 5.0 and $50.0 \mathrm{mg} / \mathrm{kg}$; eserine sulfate, .02 and $.2 \mathrm{mg} / \mathrm{kg}$; chlorpromazine hydrochloride, .5 and $5.0 \mathrm{mg} / \mathrm{kg}$; dl-amphetamine sulfate, .5 and $5.0 \mathrm{mg} / \mathrm{kg}$; and $.2 \mathrm{cc}$ of $.9 \%$ saline.

\section{Apparatus}

Tests took place with the animals in a $79 \times 79 \times 37 \mathrm{~cm}$ high box. A video recorder was used to monitor spontaneous activity. Core temperature was monitored with a rectal probe.

\section{Procedure}

Postures. In the tests, animals were placed in normal, front, side, or back postures, as shown in Figure 1. A trial consisted of placing an animal in a posture and holding it firmly until it was

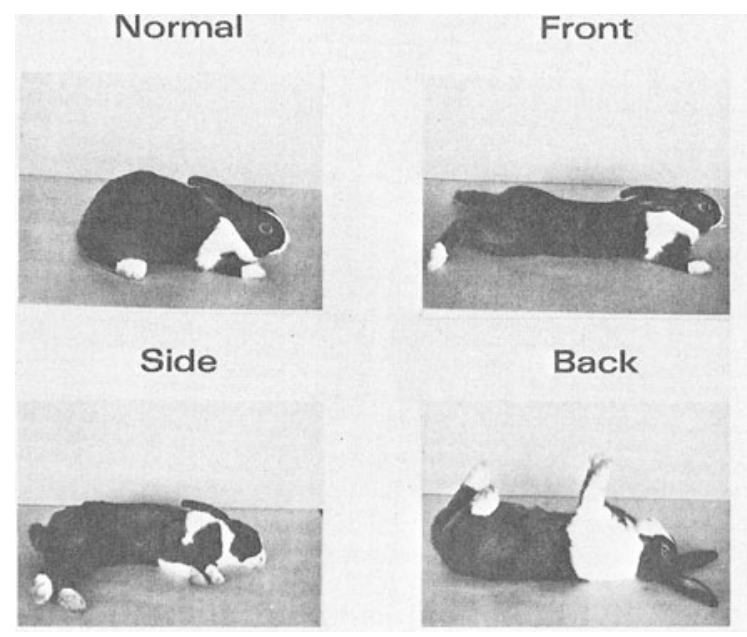

Figure 1. Postures in which the Dutch belt rabbits were placed. 
still or until $15 \mathrm{sec}$ had elapsed. The duration the animal was still (before returning to the normal posture in the case of the front, side, and back postures or making an observable head or paw movement in the case of the normal posture) was recorded. A trial ended if an animal remained still for 300 sec.

Tests. Each rabbit was habituated to the test box for $5 \mathrm{~min}$ and then core temperature was recorded and a drug administered. After a further $5 \mathrm{~min}$, core temperature was recorded and the animal was given one trial in each of the four postures. The selection of posture sequence was random, and 120-300 sec was allowed between trials. The rabbit was left undisturbed for $5 \mathrm{~min}$ while its behavior was recorded on videotape; then it was given one further trial in each position, following which

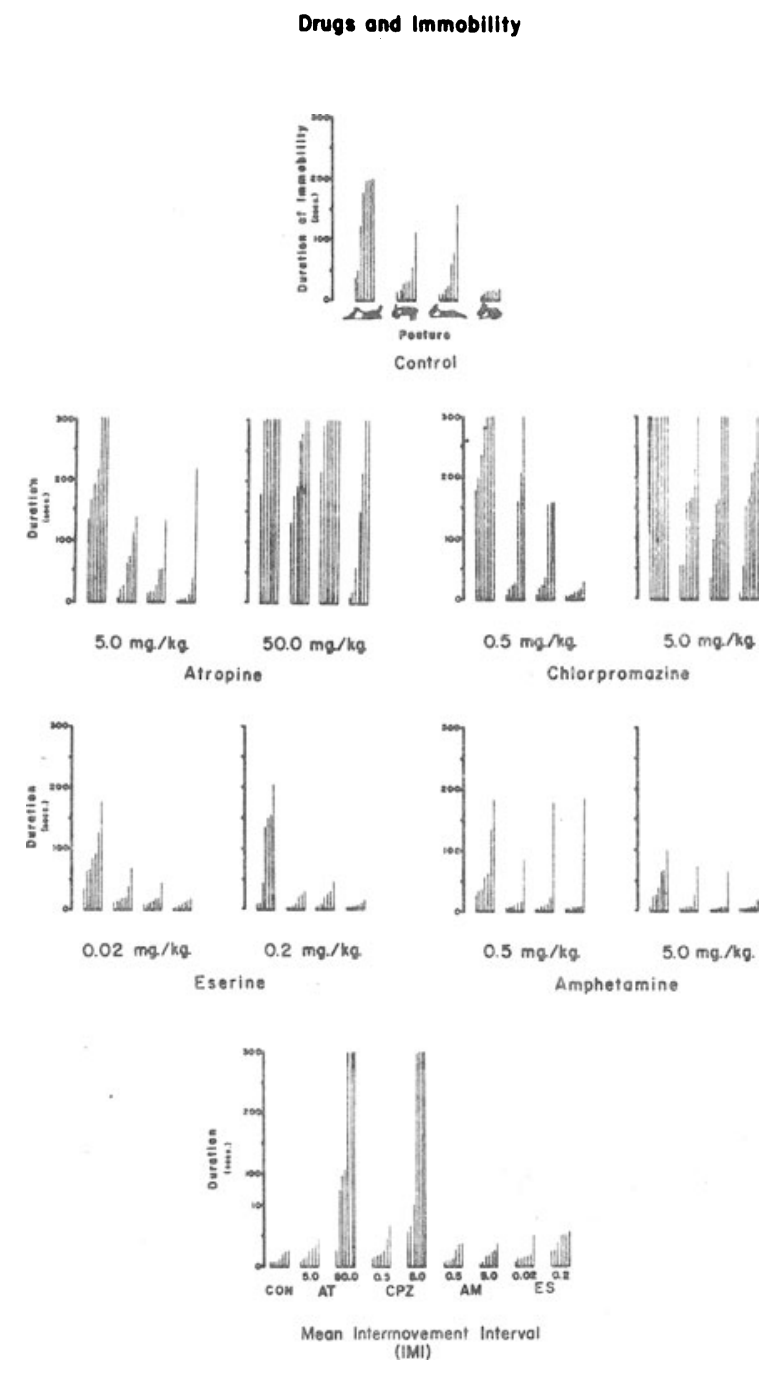

Figure 2. The effects of drugs on immobility durations shown by rabbits placed in one of four postures and on duration of intermovement intervals recorded during spontaneous activity. Note that atropine and chlorpromazine prolonged durations of immobility of rabbits placed in all postures, while eserine and amphetamine reduced durations. The high doses of atropine and chlorpromazine also increased the length of intermovement intervals. The top portion of the figure shows the durations of immobility recorded from rabbits placed in the back, side, front, and normal postures, as is indicated diagrammatically beneath the figure. This sequence is retained in the remaining figures. $\mathrm{CON}=$ control, $\mathbf{A T}=$ atropine, $\mathbf{C P Z}=$ chlorpromazine.
Table 1

Effects of Atropine, Chlorpromazine, Eserine, and Amphetamine on Durations (Mean and Standard Error) of Immobility Shown by Rabbits Placed in Various Postures

\begin{tabular}{lcccc}
\hline $\begin{array}{c}\text { Drug } \\
\mathrm{mg} / \mathrm{kg}\end{array}$ & Normal & Front & Side & Back \\
\hline Saline & $11 \pm 2$ & $50 \pm 20$ & $40 \pm 12$ & $139 \pm 27$ \\
Atropine & & & & \\
5.0 & $39 \pm 30$ & $45 \pm 16$ & $64 \pm 19$ & $230 \pm 26^{*}$ \\
50.0 & $149 \pm 47^{*}$ & $286 \pm 12^{*}$ & $234 \pm 25^{*}$ & $283 \pm 17^{*}$ \\
$\begin{array}{l}\text { Chlorpromazine } \\
.5\end{array} 13 \pm 3$ & $79 \pm 28$ & $107 \pm 44^{*}$ & $258 \pm 19^{*}$ \\
5.0 & $159 \pm 38^{*}$ & $194 \pm 41^{*}$ & $159 \pm 32^{*}$ & $297 \pm 3^{*}$ \\
Eserine & & & & \\
.02 & $10 \pm 2$ & $17 \pm 5^{*}$ & $27 \pm 8^{*}$ & $91 \pm 18^{*}$ \\
.2 & $5 \pm 2 *$ & $17 \pm 6^{*}$ & $13 \pm 5^{*}$ & $101 \pm 30^{*}$ \\
Amphetamine & & & \\
.5 & $3 \pm 20$ & $33 \pm 24^{*}$ & $20 \pm 11^{*}$ & $76 \pm 22^{*}$ \\
5.0 & $4 \pm 2 *$ & $11 \pm 9^{*}$ & $17 \pm 10^{*}$ & $47 \pm 12^{*}$ \\
\hline
\end{tabular}

*Differs from control values $t$ tests, $p<.05$.

core temperature was again recorded. Ten days were allowed between tests.

Analysis. The test sequence for each rabbit was randomized according to a balanced design. Data analysis was performed on core temperature, mean duration of immobility for each posture under each drug condition, and mean intermovement interval obtained from the 5 -min video record.

\section{RESULTS}

\section{Effect of Posture}

As suggested by Figure 2, the animals were immobile for the longest duration in the back posture, the shortest duration in the normal, and for intermediate durations in the front and side postures. Analysis of variance indicated that the effect of posture on the duration of immobility was significant in the saline condition $[\mathrm{F}(2,14)=8.90, \mathrm{p}<.001]$. Although atropine and chlorpromazine increased immobility durations, there was a similar relation between posture and duration $[F(3,18)=23.78, p<.001]$. Eserine and amphetamine decreased over all durations of immobility, but after these drugs there was still a similar significant relation between posture and immobility duration $[F(3,18)=$ $29.52, \mathrm{p}<.001]$.

\section{Atropine and Chlorpromazine}

Analysis of variance on the effects of atropine and chlorpromazine indicated there was a significant drug effect $[F(2,27)=27.03, p<.001]$. There was also a significant dosage effect $[\mathrm{F}(1,6)=97.89, \mathrm{p}<.001]$. The high doses of both drugs had a greater effect in prolonging immobility than did the low doses (Table 1). There were also significant interactions: Drug Dosage by Posture $[F(3,102)=4.23, p<.01]$, Drug Dosage by Drug $[\mathrm{F}(2,102)=22.54, \mathrm{p}<.001]$, and Drug Dosage by Drug by Posture $[F(6,102)=2.77, p<.05]$. As suggested by Table 1 , these interactions appeared to be due to the more pronounced effects the drugs had on 
the durations of immobility that were longest under the saline condition.

\section{Eserine and Amphetamine}

Analysis of variance and follow-up $t$ tests on the effects of eserine and amphetamine indicated that both drugs significantly reduced immobility durations $[F(2,12)=6.66, p<.01]$ (Figure 2). By reference to Table 1, however, it can be noted that the low doses of both drugs did not significantly reduce the immobility duration associated with the normal posture.

\section{Spontaneous Activity}

The mean duration and standard error of intermovement intervals taken from the spontaneous activity portion of the tests after the animals received saline was $1.85 \pm .3 \mathrm{sec}$. During the major portion of the tests, the animals engaged in exploratory activities. Atropine and chlorpromazine increased the duration of intermovement intervals $[\mathrm{F}(2,12)=8.02, \mathrm{p}<.05]$; however, only with the high dose of atropine (169 \pm $48 \mathrm{sec})$ and chlorpromazine $(183 \pm 55 \mathrm{sec})$ was this increase significant (t tests, $p<.05)$. After both drugs, the animals adopted a sprawling posture during which support was absent. The major activity of the animals treated with the low doses of the drugs was exploratory behavior. This is reflected in the durations of intermovement intervals: atropine, $2.4 \pm .5 \mathrm{sec}$; chlorpromazine, $5.3 \pm 3 \mathrm{sec}$.

Possibly due to baseline effects, there were no significant effects of eserine and amphetamine on intermovement intervals. After high doses of amphetamine, the animals were hyperresponsive to handling; when left undisturbed, they made stereotyped and repetitive lateral head movements. After high doses of eserine, the rabbits showed nearly continuous chewing and tremor of the limbs (which continued when they were immobilized on their backs). They also appeared uncoordinated and had difficulty executing the righting reflex.

\section{Temperature}

The effect of the drugs on body temperatures is summarized in Figure 3. Both doses of atropine and chlorpromazine significantly reduced body temperature $[F(2,12)=24.12, p<.001]$. The high doses of eserine and amphetamine significantly raised body temperature $[F(2,12)=9.90, p<.001]$. These changes in core temperature were in the opposite direction to the changes in durations of immobility.

\section{DISCUSSION}

The finding that there is a relation between the duration of immobility and posture may suggest that there are central mechanisms which selectively control immobility durations (Carli, 1968; Klemm, 1971). It might also suggest, in concert with Bonnet and Saboul (1935), Buser and Viala (1969), Kumazawa (1963), and Van Harreveld and Bogen (1961), that input from peripheral skin receptors, which might increase when an animal is on its back or side, contribute to immobility durations. Other factors which may be relevant include the force that is required to initiate a movement from a posture (Whishaw, Flannigan, \& Schallert, Note 1) and the loss of facilitation which derives from foot contact with a surface (Schallert, Whishaw, \& Teitelbaum, Note 2).

The results showing that atropine and chlorpromazine prolong, while eserine and amphetamine reduce, immobility durations are consistent with other research (Hatton et al., 1975; Klemm, 1965; Scotti de Carolis et al., 1968). We found that these pharmacological agents had a similar effect on all immobility postures as well as on immobility that occurred as a part of spontaneous behavior. Our results might suggest that the drugs influence immobility durations indirectly by activating or depressing voluntary or stereotyped motor responses. However, there was also an inverse relation between core temperature change and immobility duration. This suggests that changes in central regulatory systems may also have an influence on immobility durations. In other research we have found that warming rats or rabbits greatly prolongs, while cooling nearly abolishes, the types of immobility which occur with postures described in this paper as front, side, or back (Schallert et al., Note 2; Whishaw, Schallert, \& Teitelbaum, Note 3 ). The drugs may have influenced heat gain or heat loss systems, thus producing changes comparable to those obtained with warming and cooling the animals directly.

In summary, we suggest that further examination of the

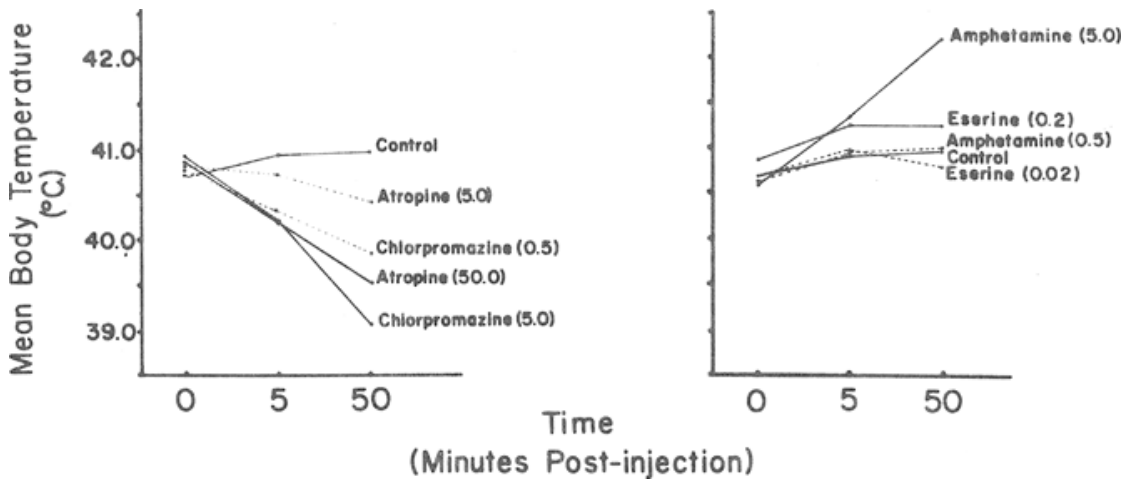

Figure 3. Mean body temperature of rabbits at 0,5 , or $50 \mathrm{~min}$ after drug injection. Note that atropine and chlorpromazine reduce core temperature, while the high doses of eserine and amphetamine raise core temperature. 
relation between posture and immobility may help clarify the relative contributions of peripheral and central influences. It seems possible to suggest that there may be multiple controls on immobility durations and that models incorporating a single neural center may not be required to explain immobility phenomena.

\section{REFERENCE NOTES}

1. Whishaw, I. Q., Flannigan, K. P., \& Schallert, T. Electroencephalographic $[E E G]$ activity in the rabbit when immobile in normal sitting or inverted postures. Unpublished manuscript.

2. Schallert, T., Whishaw, I. Q., \& Teitelbaum, P. Sources of "spontaneity" in the behavior of aphagic rats. Paper presented at the 6th International Conference on the Physiology of Food and Fluid Intake, Paris, July 1977.

3. Whishaw, I. Q., Schallert, T., \& Teitelbaum, P. The role of afferent input in maintaining EEG and motor activation. Paper presented at the meeting of the Canadian Psychological Association, Vancouver, June 1977.

\section{REFERENCES}

Bonnet, V., \& SABoul, R. Contribution à l'étude de l'hypnose animale: Modifications nerveuses centrales et phénomènes de subordination dans l'hypnose chez la grenouille. Journal de Physiologie et de Pathologie Générale, 1935, 33, 887-906.

Búser, P., \& Viala, G. A study of hypnosis in the rabbit. In L. Chertok (Ed.), Psychophysiological mechanisms of hypnosis. New York: Springer-Verlag, 1969. Pp. 28-39.

CARLI, G. Depression of somatic reflexes during rabbit hypnosis. Brain Research, 1968, 11, 453-456.
Carli, G. Animal hypnosis in the rabbit. Psychological Record, 1977, 1, 123-143.

hatton, D. C., Woodruff, M. L., \& Meyer, M. E. Cholinergic modulation of tonic immobility in the rabbit (Oryctolagus cuniculus). Journal of Comparative and Physiological Psychology, 1975, 89, 1053-1060.

KLEMM, W. R. Drug potentiation of hypnotic restraint of rabbits, as indicated by behavior and brain electrical activity. Laboratory Animal Care, 1965, 15, 163-167.

KLEMM, W. R. Neurophysiologic studies of the immobility reflex ("animal hypnosis"). In S. Ehrenpreis \& O. C. Solnitzky (Eds.), Neurosciences Research (Vol. 4). New York: Academic Press, 1971. Pp. 165-212.

Kumazawa, T. "Deactivation" of the rabbit's brain by pressure application to the skin. Electroencephalography and Clinical Neurophysiology, 1963, 15, 660-671.

Maser, J. D., \& Gallup, G. G., JR. Tonic immobility and related phenomena: A partially annotated, tricentennial bibliography, 1636-1976. Psychological Record, 1977, 1, 177-217.

Scotti de Carolis, A., Carruyo, L., \& Longo, V. G. Pharmacological and electroencephalographic data on animal hypnosis. In A. Cerletti \& F. J. Bové (Eds.), The present status of psychotropic drugs: Pharmacological and clinical aspects. (Proceedings of the VI International Congress of the Collegium Internationale Neuropsychopharmacologicum, Terragona, Spain, 24-27 April 1968.) Amsterdam: Excerpta Medica Foundation, 1968. Pp. 98-105.

Van Harreveld, A., \& Bogen, J. E. The clining position of the bulbocapnized cat. Experimental Neurology, 1961, 4, 241-261.

(Received for publication August 29, 1977.) 